\title{
Demencija sergančių pacientų priežiūros rekomendacijos COVID-19 pandemijos metu
}

\author{
E. Audronytė \\ V. Sutnikienè \\ G. Kaubrys \\ Vilniaus universitetas, \\ Neurologijos centras
}

\begin{abstract}
Santrauka. Straipsnyje apžvelgiamos JAV Alzheimerio ligos asociacijos, Europos neurologų asociacijos demencijos mokslinės darbo grupès ir Europos šalių nacionalinių Alzheimerio ligos asociacijų rekomendacijos, skirtos demencija sergančius pacientus prižiūrintiems asmenims ir ilgalaikę šių pacientų priežiūrą teikiantiems sveikatos priežiūros specialistams COVID-19 pandemijos metu. Išskiriami pagrindiniai priežiūros aspektai ir kylantys sunkumai, ị kuriuos reikètų atsižvelgti, prižiūrint demencija sergančius pacientus namuose ar jiems esant slaugos ir palaikomojo gydymo ligonineje, šioje greitai besikeičiančioje ekstremalioje situacijoje.
\end{abstract}

Raktažodžiai: demencija, Alzheimerio liga, COVID-19, pandemija.
Pasaulinis COVID-19 infekcijos plitimas lèmè, kad ši virusinė infekcija keičia daugelio sričių nusistovẻjusią tvarką, taip pat ir pacientų priežiūrą [1-4]. Demencija sergantys pacientai dažniausiai negali pasirūpinti savimi, jiems sunku prisitaikyti prie greitai besikeičiančios situacijos, reikalinga nuolatinè šeimos, artimųų pagalba ar ilgalaikẻ priežiūra slaugos ir palaikomojo gydymo ligoninèse [1,2]. Remiantis turimais duomenimis, demencija nedidina rizikos susirgti COVID-19 [1]. Vis dèlto kognityviniai sutrikimai, vyresnis amžius ir gretutinès ligos gali lemti tam tikras problemas, su kuriomis susiduriama pandemijos metu prižiūrint ir gydant pacientus, turinčius demenciją [1, 3, 4]. Todèl JAV Alzheimerio ligos asociacija, Europos neurologų asociacijos demencijos mokslinė darbo grupė ir Europos šalių nacionalinès Alzheimerio ligos asociacijos parengè rekomendacijas šių pacientų priežiūrai [1-4].

\section{PACIENTŲ PRIEŽIŪRA NAMUOSE}

Kognityvinių sutrikimų turintiems pacientams sunku suprasti, atsiminti ir vykdyti elgesio COVID-19 pandemijos metu rekomendacijas, todèl svarbu:

\author{
Adresas: \\ Eglè Audronytè \\ Neurologijos centras, \\ Vilniaus universiteto ligonine Santaros klinikos \\ Santariškiu g. 2, LT-08661 Vilnius \\ El.paštas egle.audronyte@santa.lt
}

- užrašyti priminimus ir kasdien padėti laikytis rekomenduojamų higienos taisyklių. Pavyzdžiui, vonioje padèti užrašus, primenančius plauti rankas ir kaip teisingai tą daryti $[1,3]$;

- jei pacientas nesugeba nusiplauti ranku, naudoti dezinfekcinius skysčius [1];

- esant reikalui, priminti nešioti apsaugos priemones, paprastai ir pacientui suprantamai paaiškinus, kodèl jų naudojimas yra reikalingas [1, 3, 4].

Demencija sergantys pacientai, susirgę COVID-19, gali neatpažinti pirmųų ligos simptomų ir nenurodyti jokių nusiskundimų [1-4]. Šiems pacientams pirmasis infekcijos požymis gali būti sumišimas [2,3]. Todèl, pastebejjus staiga naujai atsiradusi sumišimą, rekomenduojama susisiekti su savo bendrosios praktikos gydytoju ar kitu sveikatos priežiūros specialistu [1]. Jei nėra dusulio ar kitų kvėpavimo funkcijos sutrikimų, karščiavimo, pirmiausia rekomenduojama aptarti tolesnị ištyrimo planą su gydytoju telefonu, o ne vykti ic priėmimo skyrių [1].

COVID-19 pandemijos metu nutrauktas daugelio socialinių paslaugų teikimas, plètojamas bendravimas nuotoliniu būdu, naudojantis ịvairiomis telekomunikacijų priemonemis [1-4]. Demenciją turintys pacientai tokiomis technologijomis naudotis dažniausiai nesugeba, todèl svarbu užtikrinti, kad juos taip pat pasiektu reikalingos priemonès ir priežiūra, ypač jei demenciją turintis pacientas gyvena vienas [4].

Jei pacientui reikalinga nuolatinė priežiūra, svarbu apsvarstyti ir suplanuoti, kas būtų daroma, jei susirgtų pagrindinis pacientą prižiūrintis asmuo [1].

(C) Neurologijos seminarai, 2020. Open Access. This article is distributed under the terms of the Creative Commons Attribution 4.0 International License CC-BY 4.0 (http://creativecommons.org/licenses/by/4.0/), which permits unrestricted use, distribution, and reproduction in any medium, provided you give appropriate credit to the original author(s) and the source, provide a link to the Creative Commons license, and indicate if changes were made. 


\section{PACIENTŲ PRIEŽIŪRA SLAUGOS IR PALAIKOMOJO GYDYMO İSTAIGOSE}

COVID-19 pandemijos metu daugelyje slaugos ir palaikomojo gydymo įstaigų pacientų lankymas yra draudžiamas [2-4]. Šeimos nariams ir artimiesiems reikia suteikti informaciją, kaip jie gali sužinoti apie savo artimajị ar pasikalbėti su prižiūrinčiu personalu [2, 3]. Reikètų užtikrinti, kad įstaiga turètų bent dviejų paciento artimųjų kontaktinę informaciją [2]. Taip pat svarbu aptarti ir užtikrinti bendravimo priemones, kurios padètų pacientui išlaikyti ryšį su šeima ir artimaisiais [2-4]. Esant galimybei, paskatinti telefoninius ar vaizdo skambučius, žinučių ir nuotraukų siuntimą [2-4]. Rekomenduojama, kad su pacientu būtų bendraujama reguliariai, dažniausiai su tais pačiais žmonėmis [3].

Pandemijos metu galima greita personalo kaita ir vietos pasikeitimai, perkèlus pacientą ị kitą skyrių ar gydymo įstaigą $[2,4]$. Tai didina pacientų pasimetimą, didẻja elgesio sutrikimų, delyro rizika [2]. Pacientą prižiūrinčio asmens užduotis yra stebèti ir bandyti suprasti, ką stengiasi išreikšti sergantysis demencija, nes staigus paciento būklès pasikeitimas gali būti vienas iš infekcijos požymių [2-4]. Gali būti sunku numatyti ir reaguoti ị pasikeitusị elgesị besikeičiančioje aplinkoje, ypač kritinėmis situacijomis, todèl labai svarbu išlaikyti dienos struktūrą, ịprastą rutiną [2-4].

Paciento pažinimas yra vienas iš svarbiausių veiksnių, užtikrinant kokybišką individualią, ic asmenį orientuotą priežiūrą, todèl labai svarbu, kad šią informaciją būtų galima pasiekti net ir dažnai keičiantis personalui [2, 3]. Atsižvelgiant i tai, kad globos komanda pandemijos metu gali dažnai keistis, rekomenduojami trumpi personalo susitikimai pamainos pradžioje, kurie leistų darbuotojams sužinoti reikalingą informaciją apie slaugomus asmenis [2]. Rekomenduojama:

- informaciją apie pacientus laikyti personalui lengvai pasiekiamoje vietoje, kad kiekvienas priežiūros komandos narys galètų, esant reikalui, su ja susipažinti;

- nurodyti ne tik paciento vardą, bet ir buvusius pomègius, ịprastą dienos rutiną, miego ir valgymo ịpročius, būdingą elgesị, išlikusius gebejjimus [2].

Prižiūrint pacientus slaugos ir palaikomojo gydymo ligoninejje, labai svarbus yra rizikos užsikrèsti mažinimas [2-4]. Demencija sergantiems pacientams sunku sekti ir prisiminti instrukcijas, todèl rekomenduojama:

- priminti apie rankų plovimą, plauti rankas prižiūrint personalui pagal sudarytą rankų plovimo grafiką [2, 3];

- neleisti dèti daiktų į burną ir prižiūrèti, kad jais nebūtų dalinamasi [2];

- užtikrinti, kad būtų laikomasi socialinès distancijos, pavyzdžiui, planuoti valgymą ar užsièmimus mažomis grupemis [3].
Taip pat svarbu atsiminti, kad demenciją turintys pacientai yra linkę klajoti, gali pasimesti ir patekti į nesaugią aplinką [2, 4]. Reikėtų užtikrinti galimybę pacientams judèti ir išlaikyti fizinị aktyvumą, kartu užtikrinant saugią aplinką ir kuo mažesnę viruso plitimo riziką, kadangi reguliarus fizinis aktyvumas gerina pacientų savijautą [2-4].

Demencija sergantys pacientai dẻl vyresnio amžiaus, gretutinių ligų ir esamų kognityvinių sutrikimų sunkiau prisitaiko prie greitai besikeičiančios situacijos ir susiduria su daugeliu problemų ekstremalių situacijų, taip pat ir COVID-19 pandemijos metu [1, 2, 4]. Svarbu užtikrinti reikalingą pagalbą šiems pacientams ir juos prižiūrintiems asmenims [1-4]. Daugiau informacijos galite rasti apžvelgtose rekomendacijose (anglų kalba), kurios, tikètina, bus atnaujinamos, kaupiantis žinioms apie veiksmingus sprendimus demencija sergančių pacientų priežiūroje [1-4].

\section{Literatūra}

1. Alzheimer's Association. Coronavirus (COVID-19): Tips for dementia caregivers [cited 2020 Apr 23]. Available from: https://www.alz.org/help-support/caregiving/coronavirus(covid-19)-tips-for-dementia-care

2. Alzheimer's Association. Coronavirus (COVID-19): Tips for dementia caregivers in long-term or community-based settings [cited 2020 Apr 24]. Available from: https://www.alz.org/professionals/professional-providers/ coronavirus-covid-19-tips-for-dementia-caregivers

3. European Academy of Neurology. Dementia scientific panel report - COVID-19 [cited 2020 Apr 22]. Available from: https://www.eanpages.org/2020/04/03/dementia-scientificpanel-report-covid-19/

4. Alzheimer Europe. Alzheimer Europe recommendations on promoting the wellbeing of people with dementia and carers during the COVID-19 pandemic [cited 2020 Apr 22]. Available from: https://www.alzheimer-europe.org/Policy/ Our-opinion-on/Wellbeing-of-people-with-dementiaduring-COVID-19-pandemic

\section{E. Audronytė, V. Sutnikienė, G. Kaubrys \\ DEMENTIA CARE RECOMMENDATIONS DURING THE COVID-19 PANDEMIC}

\section{Summary}

The recommendations for dementia caregivers and health care professionals in long-term care facilities during the COVID-19 pandemic published by the Alzheimer's Association, the European Academy of Neurology Dementia Scientific Panel, and Alzheimer Europe are presented in this review article. The main aspects of care and the emerging difficulties that should be taken into account when caring for dementia patients at home and in nursing homes in this rapidly changing emergency are highlighted.

Keywords: dementia, Alzheimer's disease, COVID-19, pandemic.

Gauta:

20200429

Priimta spaudai: 20200607 